Revue d'histoire de l'Amérique française

REVUE D.HISTOIRE DE L'AMÉRIQUE FRANÇAISE

\title{
Le Professeur d'histoire, no 1, novembre 1968. Revue officielle de la Société des professeurs d'histoire du Québec. 81 p. \$1.50 le numéro.
}

\section{Michel Allard}

Volume 22, numéro 3, décembre 1968

URI : https://id.erudit.org/iderudit/302811ar

DOI : https://doi.org/10.7202/302811ar

Aller au sommaire du numéro

Éditeur(s)

Institut d'histoire de l'Amérique française

ISSN

0035-2357 (imprimé)

1492-1383 (numérique)

Découvrir la revue

Citer ce compte rendu

Allard, M. (1968). Compte rendu de [Le Professeur d'histoire, no 1, novembre 1968. Revue officielle de la Société des professeurs d'histoire du Québec. $81 \mathrm{p}$. \$1.50 le numéro.] Revue d'histoire de l'Amérique française, 22(3), 476-477.

https://doi.org/10.7202/302811ar d'utilisation que vous pouvez consulter en ligne.

https://apropos.erudit.org/fr/usagers/politique-dutilisation/ 
Le Professeur d'histoire, no 1, novembre 1968. Revue officielle de la Société des professeurs d'histoire du Québec. 81 p. $\$ 1.50$ le numéro.

En janvier 1968, la Société des professeurs d'histoire du Québec lançait le premier numéro de sa revue Le professeur d'histoire. Après quelques mois de silence, cette revue réapparaît sous une nouvelle direction. Il faut souligner l'amélioration de la présentation matérielle. Les éditions du Boréal Express ont apporté, sur le plan technique, une collaboration qu'on ne saurait passer sous silence.

Ce numéro nous présente des articles de haute qualité. Nous avons particulièrement apprécié les articles des professeurs André Ségal, Pierre Savard et Michel Brunet.

M. Ségal définit clairement la fonction de l'enseignement de l'histoire au niveau collégial. On ne doit pas préparer de futurs historiens mais "contribuer à grandir l'homme, à l'ouvrir à la dimension totale de l'humanité" (p. 9). Il soutient, à juste titre, qu'au niveau collégial on doit chercher à "développer une attitude historienne par la perspective d'un enseignement global de l'histoire, alimenté résolument par le dialogue du présent et du passé" (p.13).

Le professeur Savard dans un excellent article s'attaque au problème de la formation des maîtres. Avec une grande lucidité, l'auteur définit le problème de la formation des maîtres, souligne le peu de recherche faite en didactique de l'histoire et réclame de toute urgence qu' "un sérieux travail de coordination s'élabore entre les Facultés des Sciences de l'Education et les Ecoles Normales Supérieures ..." (p. 47). Nous ne pouvons qu'appuyer les remarques du professeur Savard. 
Le professeur Brunet, avec sa verve coutumière, fait le lien entre la crise de l'éducation au Québec et l'enseignement de l'histoire à l'université. Soulignons que dans cet article, rédigé près de sept mois avant les événements d'octobre dernier, l'auteur décèle bien les carences et les faiblesses de l'enseignement universitaire.

Il est à noter que ces trois auteurs traitent du problème de la formation des maîtres. Bien au fait de la situation de l'enseignement au Québec, ils mettent rapidement le doigt sur la pierre d'achoppement de la réforme scolaire.

Ce numéro de la revue de la Société des professeurs d'histoire du Québec contient aussi deux articles d'auteurs européens. Ces derniers apportent sans aucun doute à cette revue une dimension internationale, mais nous espérons que dans les prochains numéros une plus grande proportion du nombre de pages soit réservée aux enseignants québecois. Malgré cette réserve, nous sommes assurés que Le Professeur d'histoire connaîtra un brillant succès auprès des enseignants d'histoire du Québec.

Ecole normale Ville-Marie

MiCHEL AlLARD 